\title{
FAKTOR YANG BERHUBUNGAN DENGAN KELULUSAN UJI KOMPETENSI NERS INDONESIA (UKNI) DI REGIONAL SULAWESI
}

\author{
Ayu Hartina ${ }^{1}$, Takdir Tahir ${ }^{2, *}$, Nurhaya Nurdin², Midawati Djafar \\ ${ }^{1}$ Mahasiswa, Program Studi Ilmu Keperawatan, Fakultas Keperawatan \\ Universitas Hasanuddin, Makassar, Indonesia \\ ${ }^{2}$ Dosen, Program Studi Ilmu Keperawatan, Fakultas Keperawatan, \\ Univ. Hasanuddin, Makassar, Indonesia \\ ${ }^{3}$ Perawat Pelaksana RSUP Dr. Wahidin Sudirohusodo Makassar, Indonesia \\ *)E-mail: takdirtahir@unhas.ac.id
}

Diterima: Agustus 2017, diterbitkan: Agustus 2017

\begin{abstract}
ABSTRAK
Tujuan penelitian: Mengidentifikasi faktor-faktor yang berhubungan dengan kelulusan dalam pelaksanaan UKNI di institusi regional Sulawesi. Metode: Penelitian ini menggunakan survei analitik dengan model pendekatan cross sectional study. Penelitian ini menggunakan kuesioner dengan skala Guttman. Pengambilan data dilakukan pada 16 Desember 2016-19 April 2017, sebanyak 72 orang lulusan ners sebagai sampel dari berbagai institusi keperawatan di wilayah Sulawesi, pengambilan sampel dilakukan secara cluster sampling, lalu diberikan kuesioner saat briefing H-1 sebelum ujian kompetensi ners. Uji statistik yang digunakan yaitu uji Pearson correlation dengan tingkat kemaknaan $\mathrm{p}-$ value $=0,05$. Hasil: Ada hubungan kesiapan ujian $(\mathrm{p}=0,001)$, try out UKNI $(\mathrm{p}=0,03)$, prestasi akademik ( $\mathrm{p}=0,03)$, dan peran institusi $(\mathrm{p}=0,005)$ dengan tingkat kelulusan uji kompetensi ners dan tidak ada hubungan kondisi fisik $(\mathrm{p}=0,555)$, praktik profesi dengan tingkat kelulusan uji kompetensi ners. Kesimpulan: Faktor yang paling dominan berhubungan dengan kelulusan uji kompetensi adalah kesiapan uji kompetensi. Perlu dilakukan penelitian lanjut an yang terkait sistem bimbingan profesi dan pemahaman blueprint terhadap kelulusan uji kompetensi ners.
\end{abstract}

Kata Kunci: uji kompetensi, tingkat kelulusan, prestasi akademik

\section{FACTORS RELATED TO A PASS IN TEST OF COMPETENCE FOR INDONESIAN NURSES IN SULAWESI REGION \\ ABSTRACT}

Objective: To identify factors related to the pass in the Test of Competence for Indonesian Nurses in regional institutions of Sulawesi. Methods: This research employed analytical survey with cross sectional study approach. It used Guttman scale for the questionnaire. Data were collected from 16 December 2016 until 19 April 2017, involving 72 nursing graduates as samples from various nursing institutions in Sulawesi, taken using cluster sampling, and given questionnaire during a briefing session held one day before the test of competence for nurses. The statistical test used Pearson correlation test with significance level of $p$-value $=0.05$. Results: There was correlation of test readiness $(p=0.001)$, try-out for the Test of Competence for Indonesian Nurses ( $p=0.03)$, academic achievement $(p=0.03)$, and institutional role $(p=0.005)$ with the passing rate of the test of competence for nurses and there was correlation of physical condition $(p=0.555)$, professional practice with the passing level of the test of competence for nurses. Conclusion: The most dominant factor related to the pass in the competence test is the readiness for the competence test. It is necessary to conduct further research on professional guidance system and understanding of blueprint concerning the pass in the test of competence for nurses. 
Keywords: competence test, passing rate, academic achievement

\section{LATAR BELAKANG}

Uji Kompetensi Ners Indonesia (UKNI) adalah suatu tes atau ujian yang digunakan untuk mengukur pengetahuan, keterampilan, dan sikap sesuai dengan standar profesi ners. Uji kompetensi bertujuan untuk memastikan bahwa setiap perawat telah memiliki kompetensi yang dipersyaratkan yang dinyatakan dengan sertifikat uji kompetensi (Tim Visi Adiwidya, 2015). UKNI dimulai sejak tahun 2013 dan sampai Mei 2017 UKNI sudah dilaksanakan sebanyak 8 kali.

Pada era global ini, uji kompetensi merupakan bagian dari upaya standardisasi registrasi dan izin praktik bagi tenaga kesehatan yang akan memberikan pelayanan kesehatan di Indonesia. Tujuan uji kompetensi ini ialah untuk menstandardisasi kompetensi tenaga kesehatan Indonesia dalam memberikan pelayanan kesehatan secara paripurna kepada masyarakat dengan prinsip utama keselamatan pasien (Kementerian Riset Teknologi \& Pendidikan Tinggi Republik Indonesia, 2016).

Hasil UKNI dari tahun ke tahun mengalami tingkat kelulusan yang fluktuatif. Berdasarkan data Direktorat Penjaminan Mutu (DIRPENJAMU) dalam 3 tahun terakhir, pada tahun 2015 jumlah peserta yang mengikuti UKNI sebanyak 21.688 orang, peserta yang dinyatakan lulus berjumlah 10.806 orang $(45,45 \%)$ sedangkan peserta yang dinyatakan tidak lulus mencapai 10.882 orang (53,61 \%) (Masfuri, 2016).

Pada UKNI tahun 2015, dilaporkan bahwa jumlah peserta yang ikut UKNI periode ke-5 sebanyak 10.053 orang, peserta yang dinyatakan lulus berjumlah 4.569 orang $(45,4 \%)$, dan peserta yang dinyatakan tidak lulus mencapai 5.484 orang (54,6\%). Pelaksanaan UKNI tahun 2016 periode ke-6 jumlah peserta yang ikut UKNI sebanyak 11.635 orang, peserta yang dinyatakan lulus berjumlah 6.237 orang $(53,6 \%)$, dan peserta yang dinyatakan tidak lulus 5.398 orang $(46,4 \%)$. Data UKNI di Sulawesi periode ke-7 jumlah peserta yang ikut UKNI sebanyak 3.879 orang, yang dinyatakan lulus hanya berkisar 895 orang (23\%), dan peserta yang tidak lulus mencapai 2.984 orang (77\%). Sementara itu, pada UKNI periode ke-8 bulan November peserta yang ikut UKNI berjumlah sekitar 4.332 orang, peserta yang dinyatakan Iulus UKNI hanya berkisar 972 orang (22\%), dan peserta yang dinyatakan tidak lulus mencapai 3.350 orang (78\%). Berdasarkan data tersebut, dapat disimpulkan bahwa secara nasional, dalam tiga periode berturutturut jumlah peserta tidak lulus semakin meningkat. Jika tidak dikendalikan dengan segera, hal ini akan memberikan dampak pada instutisi dan profesi.

Kita lihat uji kompetensi di negara lain, misalnya di Amerika, sistem ujiannya disebut NCLEX (Nursing Council Liceransure Examination). NCLEX adalah suatu sistem ujian dengan komputerisasi untuk mengetahui kemampuan seorang perawat, baik dalam hal kognitif, skill, maupun attitude sehingga mampu memberikan asuhan keperawatan secara aman dan efektif di segala tingkat pelayanan keperawatan. Hasil ujian NCLEX ini akan menjadi dasar bagi National Council of State Board of Nursing (NCSBN) dalam memberikan lisensi sebagai practical nursing (PN) atau register nurse (RN)(NCSBN, 2009). Hal ini sama dengan pelaksanaan uji kompetensi perawat di Indonesia saat ini.

Terdapat berbagai faktor yang dapat memengaruhi tingkat kelulusan dalam mengikuti uji kompetensi. Faktor-faktor yang memiliki pengaruh secara signifikan terhadap kemampuan mahasiswa untuk lulus uji kompetensi ialah faktor akademik, faktor kognitif, dan faktor individu (Sears, 
Othman, \& Mahoney, 2015). Beberapa faktor yang berpengaruh terhadap keberhasilan uji kompetensi dari segi persiapan mahasiswa dalam belajar ialah motivasi, kemampuan membaca, catatan, manajemen waktu, dan kemampuan berpikir kritis (Professional Development and Conferencing Services, Faculty of Medicine, Memorial University of Newfoundland, 2010).

Menurut Hyland (2012), hasil kelulusan uji kompetensi yang berpusat di Amerika Serikat atau NCLEX berfokus pada bimbingan mahasiswa, mengatasi kecemasan, dan mengembangkan strategi pada program remedial. Selain itu, salah satu elemen upaya untuk sukses NCLEX bergantung pada mahasiswa, dosen, dan institusi atau biasa disebut three nodal. Faktor-faktor tersebut merupakan hasil penelitian untuk uji kompetensi perawat atau NCLEX yang diselenggarakan di Amerika Serikat. Hasil penelitian tersebut dapat dijadikan sumber utama terkait dengan faktor-faktor yang dapat memengaruhi uji kompetensi perawat di Indonesia.

Penelitian yang dilakukan oleh Nugroho (2016) menunjukkan bahwa tingkat persepsi mahasiswa profesi PSIK FK UGM tentang peran institusi pendidikan dalam pelaksanaan UKNI dalam kategori baik. Penelitian ini merupakan penelitian pertama tentang UKNI, tetapi hanya melihat dari segi persepsi mahasiswa. Hal tersebut dapat dijadikan sumber untuk mengetahui pengaruh peran institusi terhadap tingkat kelulusan dalam pelaksanaan UKNI.

Berdasarkan faktor-faktor tersebut, dapat disimpulkan bahwa tingkat kelulusan mahasiswa dapat dipengaruhi oleh faktor internal (faktor yang berasal dari dalam diri individu) dan faktor eksternal (faktor yang berasal dari luar diri individu). Faktor internal terdiri atas intelegensi, kondisi psikis, kesiapan ujian, kondisi fisik, dan prestasi akademik. Sementara itu, faktor eksternal terdiri atas keluarga dan peran institusi, tetapi sampai saat ini masih sedikit penelitian yang melaporkan hal tersebut. Oleh sebab itu, peneliti ini bertujuan mengidentifikasi faktorfaktor yang memengaruhi tingkat kelulusan dalam pelaksanaan uji kompetensi ners Indonesia di institusi regional Sulawesi.

\section{METODE}

Metode yang digunakan pada penelitian ini ialah metode penelitian kuantitatif dengan desain survei analitik. Pendekatan yang digunakan dalam penelitian ini ialah cross sectional study, dengan teknik pengambilan sampel dengan cluster sampling. Jumlah sampel diperoleh dengan mengambil sampel dari beberapa institusi negeri dan swasta yang berlokasi di regional Sulawesi. Populasi pada penelitian ini ialah semua lulusan ners, baik yang lulus maupun yang tidak lulus Uji Kompetensi Ners Indonesia regional Sulawesi periode tahun 2015-2016 yang berjumlah sekitar 4.332 orang. Adapun besar sampel pada penelitian ini sebanyak 72 orang dengan menggunakan rumus Isaac \& Michael berdasarkan kriteria inklusi ners yang lulus maupun yang belum lulus uji kompetensi, first taker maupun retaker.

Sebanyak 72 orang sampel dibagi dalam 2 kelompok yang terdiri atas 36 orang yang lulus UKNI dan 36 orang yang tidak lulus UKNI. Selanjutnya, responden diberi kuesioner yang terdiri atas dua bagian instrumen. Instrumen A meliputi data demografi yang meliputi inisial responden, usia, jenis kelamin status kerja, lama lulus ners, IPK, asal institusi, dan status keikutsertaan dalam try out UKNI. Instrumen B menggunakan skala Guttman yang meliputi kesiapan ujian yang terdiri atas 10 pertanyaan dengan kategori siap dan tidak siap yang ditentukan berdasarkan nilai mean, peran institusi yang terdiri atas 5 pertanyaan dengan kategori baik dan kurang 
baik yang ditentukan berdasarkan nilai mean, sedangkan sistem praktik profesi yang terdiri atas 8 pertanyaan dengan kategori baik dan kurang baik ditentukan berdasarkan nilai mean. Hal yang sama juga ada pada kuesioner kondisi fisik dan keikutsertaan try out.

Kuesioner diberikan saat responden mengikuti briefing $\mathrm{H}-1$ sebelum pelaksanaan ujian kompetensi ners Indonesia periode April 2017. Instrumen yang digunakan diadopsi dari blueprint uji kompetensi ners. Peneliti mengembangkannya sendiri dan selanjutnya dilakukan uji validitas dengan product moment dengan nilai $r=0,83$, dan uji reliabilitas dengan Cronbach's alpha dengan nilai $r=0,87$. Data dikumpulkan dan dianalisis menggunakan uji Chi square dengan nilai kemaknaan $p \leq 0,05$. Penelitian ini telah mendapatkan rekomendasi persetujuan etik dari Komite Etik Penelitian Kesehatan Universitas Hasanuddin No. 60/H.4.8.4.5.31/PP36-KOMETIK/2017.

\section{HASIL}

Tabel 1. Karakteristik responden berdasarkan umur, jenis kelamin, status kerja, status keikutsertaan UKNI

\begin{tabular}{|c|c|c|c|c|c|c|}
\hline \multirow[t]{3}{*}{ Karakteristik } & \multicolumn{4}{|c|}{ Kelompok } & \multicolumn{2}{|c|}{ Total } \\
\hline & \multicolumn{2}{|c|}{ Lulus } & \multicolumn{2}{|c|}{ Tidak Lulus } & \multirow[b]{2}{*}{$\mathrm{n}$} & \multirow[b]{2}{*}{$\%$} \\
\hline & $\mathrm{n}$ & $\%$ & $\mathrm{n}$ & $\%$ & & \\
\hline \multicolumn{7}{|l|}{ Jenis Kelamin } \\
\hline Laki- laki & 6 & 8.3 & 6 & 8,3 & 12 & 16,7 \\
\hline Perempuan & 30 & 41,7 & 30 & 41,7 & 60 & 83,3 \\
\hline \multicolumn{7}{|l|}{ Status Kerja } \\
\hline Kerja & 9 & 12,5 & 9 & 12,5 & 18 & 25 \\
\hline Tidak kerja & 27 & 37,5 & 27 & 37,5 & 54 & 75 \\
\hline \multicolumn{7}{|l|}{ Lama Lulus Ners } \\
\hline 1 tahun & 26 & 36,1 & 17 & 23,6 & 43 & 59,7 \\
\hline 2 tahun & 8 & 11,1 & 12 & 16,7 & 20 & 27,8 \\
\hline 3 tahun & 2 & 2,8 & 7 & 9,7 & 9 & 12,5 \\
\hline \multicolumn{7}{|l|}{ Status Keikutsertaan } \\
\hline First taker & 27 & 37,5 & 0 & 0 & 27 & 37,5 \\
\hline Retaker & 9 & 12,5 & 19 & 26,4 & 28 & 38,9 \\
\hline Retaker $>1$ kali & 0 & 0 & 17 & 23,6 & 23,6 & 23,6 \\
\hline
\end{tabular}

Tabel 1 menunjukkan hasil analisis distribusi responden berdasarkan jenis kelamin bahwa pada laki-laki maupun perempuan, ketidaklulusan dalam UKNI sama banyak, yaitu 30 orang $(83,3 \%)$. Pada kategori status kerja, responden yang lulus UKNI lebih banyak pada kelompok yang tidak kerja, yaitu 27 orang (75\%). Pada lama kelulusan ners dengan lulus UKNI, rata-rata 1 tahun kelulusannya lebih tinggi $(36,1 \%)$, yaitu 26 orang dibandingkan dengan yang lebih 2-3 tahun. Sementara itu, kategori status keikutsertaan UKNI first taker mendominasi responden yang lulus, yaitu 27 orang $(75 \%)$, sedangkan pada responden yang tidak lulus didominasi oleh retaker 1 kali, yaitu 19 orang $(52,8 \%)$. 
Tabel 2. Hubungan kesiapan ujian dengan tingkat kelulusan UKNI di institusi regional Sulawesi $(\mathrm{n}=72)$

\begin{tabular}{|c|c|c|c|c|c|c|c|}
\hline \multirow{3}{*}{ Variabel } & \multicolumn{4}{|c|}{ Kelompok } & \multirow{2}{*}{\multicolumn{2}{|c|}{ Total }} & \multirow{3}{*}{ p value } \\
\hline & \multicolumn{2}{|c|}{ Lulus } & \multicolumn{2}{|c|}{ Tidak Lulus } & & & \\
\hline & $\mathbf{n}$ & $\%$ & $\mathbf{n}$ & $\%$ & $\mathrm{n}$ & $\%$ & \\
\hline Kesiapan Ujian & & & & & & & \multirow{3}{*}{$0,001^{*}$} \\
\hline Siap & 35 & 59,3 & 24 & 40,7 & 59 & 100 & \\
\hline Tidak Siap & 1 & 7,7 & 12 & 92,3 & 13 & 100 & \\
\hline \multicolumn{8}{|l|}{ Prestasi Akademik } \\
\hline$<3,00$ & 2 & 28,6 & 5 & 71,4 & 7 & 100 & \multirow{3}{*}{$0,033^{*}$} \\
\hline $3,00-3,50$ & 9 & 34,6 & 17 & 65,4 & 26 & 100 & \\
\hline$>3,50$ & 25 & 64,1 & 14 & 35,9 & 39 & 100 & \\
\hline \multicolumn{8}{|l|}{ Kondisi fisik } \\
\hline Sehat & 35 & 50,7 & 34 & 49,3 & 69 & 100 & \multirow[t]{2}{*}{0,555} \\
\hline Sakit & 1 & 33,3 & 2 & 66,7 & 3 & 100 & \\
\hline \multicolumn{8}{|l|}{ Peran institusi } \\
\hline Baik & 36 & 55,4 & 29 & 44,6 & 65 & 100 & \multirow[t]{2}{*}{$0,005^{*}$} \\
\hline Kurang & 0 & 0 & 7 & 100 & 7 & 100 & \\
\hline \multicolumn{8}{|l|}{ Keikutsertaan TO } \\
\hline Tidak Pernah & 1 & 33,3 & 2 & 66,7 & 3 & 100 & \multirow{3}{*}{$0,030^{*}$} \\
\hline 1 kali & 15 & 37,5 & 25 & 62,5 & 40 & 100 & \\
\hline$>1$ kali & 20 & 69 & 9 & 31 & 29 & 100 & \\
\hline \multicolumn{8}{|l|}{ Sistem praktik profesi } \\
\hline Baik & 27 & 52,9 & 24 & 47,1 & 51 & 100 & \multirow[t]{2}{*}{0,437} \\
\hline Kurang & 9 & 42,9 & 12 & 57,1 & 21 & 100 & \\
\hline
\end{tabular}

Uji Chi Square $^{*}=\mathrm{p} \leq 0,05$

\section{DISKUSI}

Hasil penelitian ini menunjukkan bahwa faktor-faktor yang berhubungan secara signifikan dengan tingkat kelulusan UKNI antara lain kesiapan ujian $(p=0,001)$, prestasi akademik $(p=0,03)$, peran institusi $(p=0,005)$, frekuensi keikutsertaan try out $(p=0,03)$. Sementara itu, faktor yang tidak berhubungan dengan kelulusan UKNI pada penelitian ini ialah sistem praktik profesi $(p=0,437)$ dan kondsi fisik $(p=0,555)$.

a. Kesiapan uji kompetensi dengan tingkat kelulusan UKNI

Hasil penelitian menunjukkan bahwa peserta ujian yang memiliki kesiapan ujian yang baik berbanding lurus dengan hasil kelulusan UKNI. Semakin baik persiapan ujiannya, kelulusan UKNI semakin tinggi.
Kesiapan ujian dalam penelitian ini meliputi pemahaman mahasiswa tentang blueprint uji kompetensi, meliputi jumlah butir soal pertinjauan, jumlah soal terbanyak dalam paket soal, dan strategi menjawab soal berdasarkan tinjauan mata ajar memberikan pemahaman yang baik dengan soal-soal ujian kompetensi (Nugroho, 2016). Hasil penelitian ini sejalan dengan Kholifah \& Kusumawati (2016) yang mengatakan bahwa hambatan yang menjadi penyebab kegagalan lulusan ners dalam UKNI adalah ketidaktahuan tentang konsep UKNI, terutama tentang kisikisi UKNI atau blueprint. Blueprint UKNI juga sangat penting diketahui oleh peserta UKNI karena berisi ruang lingkup soal yang akan diujikan sehingga dapat dijadikan acuan 
untuk belajar agar lebih fokus (Kariasa et al., 2018).

b. Prestasi akademik dengan tingkat kelulusan UKNI

Hasil penelitian menunjukkan bahwa prestasi akademik berhubungan secara signifikan dengan tingkat kelulusan UKNI. Semakin tinggi nilai prestasi akademik, semakin tinggi tingkat kelulusan dalam UKNI.

Mahasiswa yang memiliki indeks prestasi kumulatif (IPK) yang baik pada tahap akademik akan lebih mudah memahami konsep ataupun teori-teori yang telah diperoleh dan akan lebih mudah mengingat serta kemampuan analisisnya lebih meningkat sehingga mahasiswa tersebut akan mudah mengerjakan soal ujian dan hasil yang didapat juga akan memuaskan (Khasanah et al., 2017). Hal ini disebabkan kemiripan pada program pendidikan akademik dan UKNI yang cenderung terpusat pada ranah kognitif. Hasil penelitian ini sejalan dengan penelitian yang dilakukan oleh Abdillah (2016) yang melaporkan bahwa ada hubungan indeks prestasi kumulatif dengan kelulusan UKNI.

c. Keikutsertaan try out (TO) UKNI dengan tingkat kelulusan UKNI

Hasil penelitian ini menunjukkan bahwa keikutsertaan TO UKNI berperan dalam kelulusan UKNI. Jika dilihat dari frekuensinya, responden yang mengikuti TO UKNI 1 kali peluang kelulusannya sebanyak $37,5 \%$. Sementara itu, responden yang mengikuti try out $\mathrm{UKNI}>1$ kali peluang kelulusannya sebanyak $2069 \%$.

Hasil penelitian ini sejalan dengan penelitian dari Abdillah (2016) yang menunjukkan bahwa ada hubungan antara try out UKNI dan kelulusan UKNI dengan nilai $p=0,000$. Mahasiswa yang telah mengikuti try out akan lebih siap mengerjakan soal ujian daripada mahasiswa yang tidak mengikuti try out karena mereka telah memiliki gambaran soal sehingga hasilnya akan lebih baik.
TO UKNI mampu memberikan gambaran mengenai model soal yang akan digunakan pada saat ujian kompetensi yang sebenarnya. Selain itu, TO dapat menjadi bahan evaluasi peserta didik untuk mengetahui kesiapan dalam mengikuti UKNI.

TO merupakan suatu mekanisme yang digunakan sebagai sebuah latihan bagi seseorang sebelum melaksanakan ujian yang sesungguhnya. TO hanyalah sebagai media untuk berlatih mengerjakan soal. Semakin sering berlatih, peserta didik akan semakin siap untuk menghadapinya karena kesuksesan itu dimulai dari banyaknya latihan atau persiapan yang matang.

Hasil penelitian ini juga menunjukkan beberapa penyebab soal try out yang sulit dijawab, antara lain soal yang panjang $(14,5 \%)$, soal yang kompleks $(7,2 \%)$, soal yang panjang dan kompleks $(73,9 \%)$, dan kasus yang tidak lazim (4,3\%). Dengan demikian, dapat disimpulkan bahwa peserta UKNI dominan sulit menjawab soal try out UKNI karena soal yang panjang dan kompleks. Hasil penelitian ini dapat menjadi masukan untuk pihak penyelenggara sesuai dengan pernyataan Kariasa et al. (2013), yaitu pengembangan soal secara baik masih perlu satu tahapan lagi, yakni try out soal. Soal hasil dari try out akan dianalisis sehingga menghasilkan soal yang berkriteria baik dan berkualitas sehingga dapat meningkatkan kelulusan.

d. Sistem praktik Profesi dengan Tingkat kelulusan UKNI

Hasil penelitian ini menunjukkan bahwa tidak terdapat hubungan antara sistem praktik profesi dan tingkat kelulusan UKNI dengan nilai $p=0,437$. Jika dilihat dari frekuensinya, responden yang memiliki sistem praktik profesi yang baik berjumlah 51 orang, yakni responden yang lulus sebanyak 27 orang $(52,9 \%)$ dan responden yang tidak lulus sebanyak 24 orang $(47,1 \%)$. Sementara 
itu, responden yang memiliki sistem praktik profesi yang kurang berjumlah 21 orang, yakni responden yang lulus sebanyak 9 orang $(42,9 \%)$ dan responden yang tidak lulus sebanyak 12 orang $(57,1 \%)$. Data tersebut menunjukkan bahwa responden yang lulus mendominasi sistem praktik profesi yang baik dibandingkan responden yang tidak lulus dan sebaliknya.

Hal tersebut menunjukkan bahwa sistem praktik profesi sangat berhubungan, tetapi frekuensi yang terlihat tidak signifikan. Namun, pengalaman klinik yang diperoleh saat pendidikan profesi dapat melatih skill dan mengaplikasikan teori yang didapatkan saat tahap akademik. Kasus-kasus yang didapatkan saat praktek profesi dapat dianalisis untuk menjawab soal soal UKNI.

Hasil penelitian ini tidak sejalan dengan pendapat dari Jefferys, Hodges, \& Trueman (2017) yang menyatakan bahwa kurikulum yang terintegrasi dan berbasis kompetensi terdiri dari dua tahapan, yaitu tahap akademik dan tahap profesi. Agar kompetensi ini dapat dicapai, mahasiswa wajib mendapatkan proses pembelajaran secara berkelanjutan antara teori dan pengalaman belajar di lahan praktik dalam suatu lingkungan yang mendukung pertumbuhan dan pembinaan kemampuan profesional. Hal tersebut berkaitan dengan UKNI, yakni uji kompetensi ini merupakan standar dalam kurikulum terintegrasi yang terdiri atas teori pada tahap akademik dan pengalaman klinik pada tahap praktik profesi (Haryanti et al., 2016). Namun, dalam penelitian ini sistem praktik profesi tidak memiliki hubungan dengan tingkat kelulusan ners. Akan tetapi, dari segi frekuensi, sistem praktik profesi cenderung berhubungan, tetapi nilainya tidak signifikan. e. Kondisi fisik dengan tingkat kelulusan UKNI

Hasil penelitian ini menunjukkan bahwa tidak terdapat hubungan antara kondisi fisik dan tingkat kelulusan UKNI dengan nilai $p=$ 0,555 . Nilai ini lebih besar daripada $\alpha(0,05)$. Jika dilihat dari frekuensinya, responden yang memiliki kondisi fisik yang sehat berjumlah 69 orang, yakni responden yang lulus sebanyak 35 orang $(50,7 \%)$ dan responden yang tidak lulus sebanyak 34 orang (49,3\%). Sementara itu, responden yang memiliki kondisi fisik yang sakit berjumlah 3 orang, yakni responden yang lulus sebanyak 1 orang $(33,3 \%)$ dan responden yang tidak lulus sebanyak 2 orang $(66,7 \%)$. Data tersebut menunjukkan bahwa kelompok yang lulus maupun tidak lulus mendominasi kondisi fisik yang sehat. Dalam penelitian ini sebagian besar responden memiliki kondisi fisik yang sehat, tetapi tidak lulus UKNI. Hal ini dipengaruhi oleh faktor lain seperti kecemasan dan juga stres menjelang ujian, akan tetapi, kondisi fisik juga sangat penting saat mengikuti uji kompetensi karena jika kesiapan fisik kurang, akan dapat berpengaruh terhadap konsentrasi saat mengikuti uji kompetensi (Li et al., 2015).

Hasil penelitian ini sejalan dengan penelitian Nyangena, Getanda, \& Ngugi (2013) yang menjelaskan bahwa kondisi fisik yang sakit atau stres dan cemas menjadi penyebab sulit untuk menyelesaikan soalsoal uji kompetensi yang membutuhkan konsentrasi penuh. Seorang calon peserta uji kompetensi harus menjaga kondisi fisik hingga pelaksanaan uji kompetensi. Jika pada saat uji kompetensi kondisi fisik tidak mendukungnya, ujian yang dihadapi akan terhambat. Akibatnya, fokus menghilang dan jawaban yang dipilih menjadi tidak tepat dan akhirnya gagal.

\section{SIMPULAN}

Berdasarkan hasil penelitian ini disimpulkan bahwa faktor yang berhubungan dengan tingkat kelulusan ners dalam pelaksanaan UKNI di regional Sulawesi ialah 
kesiapan ujian, prestasi akademik, peran institusi, dan try out UKNI.

Hasil penelitian ini diharapkan menjadi data penunjang untuk perbaikan sistem di institusi untuk lebih mempersiapkan peserta didiknya dalam pelaksanaan UKNI seperti sosialisasi UKNI, pengaplikasian soal soal berbasis kasus sejak dini, serta pendampingan/pembimbingan sebelum mengikuti UKNI. Selain itu, penelitian ini diharapkan dapat menjadi masukan kepada mahasiswa agar lebih mempersiapkan diri sebelum menghadapi UKNI baik dari segi pemahaman konsep UKNI, blueprint UKNI, serta bimbingan dan latihan soal.

\section{DAFTAR PUSTAKA}

Abdillah, A. (2016). Analisis faktor-faktor yang mempengaruhi kelulusan uji kompetensi ners Indonesia. Jurnal Penelitian Administrasi Publik, 2(2): 373-380.

Haryanti, F., Kamil, H., Ibrahim, K., Hadi, M. (Ed). (2016). Kurikulum Inti Pendidikan Ners Indonesia 2015. Jakarta Selatan: Asosiasi Institusi Pendidikan Ners Indonesia (AIPNI).

Hyland, J. R. (2012). Building on the Evidence: Interventions Promoting NCLEX Success. OJN, 2(3): 231-238.

Jefferys, D. T., Hodges, S., \& Trueman, M. S. (2017). A strategy for success on the national council licensure examination for at-risk nursing students in historically Black Colleges and Universities: A Pilot Study. International Journal of Caring Sciences, 10(3): 1705-1709.

Kariasa, I. M., Masfuri, Iriana, P., Supartini, Y., Herawati, T., Aulawi, K., Suardana, I. K., .., Zukhri, S. (2013). Blue Print Uji Kompetensi Perawat Indonesia. Naskah tidak dipublikasikan.

Khasanah, U., Sudiyanto, H., Ariyanti, F. W., Fatmawati, A. (2017). Analisis faktor- faktor yang berhubungan dengan tingkat kelulusan uji kompetensi mahasiswa S1 Keperawatan di STIKES Majapahit Mojokerto. Medica Majapahit: Jurnal IImiah Kesehatan, 9(2): 182-192.

Kholifah, S. \& Kusumawati, W. (2016). Hambatan Lulusan Ners dalam Menghadapi Uji Kompetensi Ners Indonesia. The Indonesian Journal of Health Science, 7(1): 40-47.

Li, N., Li, B., Dou, J., Wang, X. (2015). The anxiety and influence factor of the nurse students in different levels before the NCLEX-RN. Iran J Public Health, 44(4): 588-589.

Masfuri. (2016). Uji kompetensi perawat di Indonesia. JPPNI, 1(1): 87-92.

National Council of State Board of Nursing (NCSBN). (2009). 2009 NCLEX® Examination Candidate Bulletin. Chicago: NCSBN NCLEX® Examination. Nugroho, A. S. (2016). Gambaran persepsi mahasiswa profesi PSIK FK UGM tentang uji kompetensi ners Indonesia (Skripsi). Program Studi IImu Keperawatan, Fakultas Kedokteran, Universitas Gadjah Mada, Yogyakarta, Indonesia.

Nyangena, E., Getanda, A., Ngugi, S. (2013). Factors influencing success of bachelor of science in nursing graduates in nursing council of Kenya licensure examinations. Baraton Interdisplinary Research Journal, 3(1): 11-21.

Professional Development and Conferencing Services, Faculty of Medicine, Memorial University of Newfoundland. (2010). Preparing for the Registered Nurse Examination: Internationally Educated Nurses Preparing for the Registered Nurse Examination: Internationally Educated Nurses. Retrieved from http:// www.practicenl.ca/nursing/media/ien_-preparing_for_crne.pdf 
Ristekdikti. (2016). Implementasi uji kompetensi nasional bidang kesehatan sebagai langkah konkrit penjaminan mutu pendidikan tinggi kesehatan. Retrieved from https://ristekdikti.go.id/ implementasi-uji-kompetensi-nasionalbidang-kesehatan-sebagai-langkahkonkrit-penjaminan-mutu-pendidikantinggi-kesehatan/

Sears, N. A., Othman, M., \& Mahoney, K. (2015). Examining the Relationships between NCLEX-RN Performance and Nursing Student Factors, Including Undergraduate Nursing Program Performance: A Systematic Review. Journal of Nursing Education and Practice, 5(11): 10-15.

Tim Visi Adiwidya. (2015). Panduan lulus UKNI uji kompetensi ners Indonesia: Langkah mudah lolos tes profesi keperawatan. Jakarta Selatan: Visimedia Pustaka.

Wahyuni, S., Kariasa, I. M., Tahir, T., Rahayu, U., Santoso, A., Slametiningsih, Soesanto, E., Probowati, R. (2018). SiNERSI Hadirkan Sukses Uji Kompetensi Ners Indonesia. Jakarta Selatan: Asosiasi Institusi Pendidikan Ners Indonesia (AIPNI). 